\title{
Investigating the Perception of Student Teachers in Hong Kong
}

\section{Towards Peer-editing}

\author{
Kelvin, KaYu CHONG \\ English Language Teaching Unit, The Chinese University of Hong Kong \\ Tel: 852-6185-1907Ｅ-mail: iowacu@gmail.com
}

\begin{abstract}
Despite its popularity in other countries, like America and Canada, peer editing is considered quite 'avant-garde' in the Hong Kong academic community and has never been a common practice in local secondary schools' classrooms. This paper will try to unveil the reasons why a number of Hong Kong English teachers are reluctant to use peer-editing. It is hypothesized that any positive experience of peer editing among teachers themselves is an impetus to use peer editing in class. Based on this hypothesis, a brief survey was carried out to examine a group of fifteen student-teachers' attitudes who had taken a second language writing course in a graduate school's setting, in which peer-editing activities of each other's work over six weeks, in six one-hour blocks, were conducted. Reservations concerning adopting peer-editing were observed among the student-teachers' future classes. All forms of resistance and reservations, according to the participants, were claimed to derive from external constraints. A closer look, however, suggests that none of these given constraints were purely external. Rather, I believe these teachers might have either been prejudiced or neglected 'locus of control', which refers to the possible control and power a teacher possess over their classes. This paper looks at both the teachers' personalities, characterized by skeptical beliefs in peer-editing, and the external constraints from the local social situations that contribute to the resistance and reluctance of teachers implementing peer editing in Hong Kong's education institutions.
\end{abstract}

Keywords: Locus of control, Peer editing, External constraints, Teachers' personality

\section{Introduction}

Peer editing is believed to enhance students' learning through larger amounts of feedback and shorter periods of time needed than feedback given by their teachers (Gibbs, 1999, cited in Liu \& Carless, 2006). In addition, peer editing enriches the information pool for a learner's later self-assessment used for individual language development (Boud, 1995, cited in Liu \& Carless, 2006). More importantly, it opens up the opportunity to learn from individual domain to public domain by engaging a real audience. Despite its many merits, the practice of peer-editing tends to be unknown or forgone by teachers and students in Hong Kong. The issue is intriguing to me because it was only in a university writing class at master level was I introduced and exposed to this collaborative writing approach. I could see a great deal of potential benefits for my future students but it puzzled me that none of my teachers in my earlier education taught or encouraged the practice of peer editing. The question is why peer editing is still considered 'innovative' to the majority of teachers and students in local secondary schools.

Heron and Curtis (1999) pointed out that "one of the possible reasons for this approach still being innovative in Hong Kong schools might relate to the fact that so few teachers had any experience of it while they themselves were in school, particularly at primary school" ( $p$ 109-110). In other words, by the time teachers receive peer editing training at university or other higher education institutions, they are still very unfamiliar with the practice. In response to this, a post-course questionnaire (see Appendix 1) was distributed to a group of fifteen student teachers who had participated in a university masters course called Second Language Writing where they needed to participate in peer-editing each other's essays over six weeks, in six one-hour blocks. Most of them were practicing teachers in secondary schools while some of them (five out of fifteen) were full-time students. Among all the students, eight of them responded to the questionnaire. One of them was interviewed in order to elicit further information. In addition, two students who received their education in America were interviewed to gather data as a contrast to the local voices.

The objective of the study was modified slightly because of the student-teachers lacking peer editing knowledge and experience. The study originally intended to investigate the change of students' perceptions towards peer-editing and the likelihood of using it in their classes after they peer-edited their colleagues' essays. Later, it was changed to studying the students' perception towards peer-editing, and the likelihood of using peer-editing in their classrooms after a brief and initial exposure. Of course, whether teachers will use peer-editing approach later in their classes depend on many different sets of factors, both internal and external. Although the significance of external factors should not be ignored, the present paper, however will focus on the discussion of internal factors which are often neglected by teaching practitioners, especially those who taught in primary and secondary schools in Hong Kong. This approach, I must 
nevertheless concede, necessarily skirts some arguments that may be deemed important and may even present an incomplete picture of the whole situation happening in Hong Kong's education system; however, by the same token, it allows for more focused discussions.

\section{Rationale of the study}

The rationale of the study is that the student-teachers who have tried peer-editing among themselves should be more likely to see its benefits than those who have not and thus they should be more willing to apply it in their classes. It hypothesizes that any positive experience of peer editing among teachers themselves would result in a higher likelihood of their using peer editing in class. The objective of the present paper is therefore to examine their perceptions of peer-editing after the course and see how their previous classroom experiences affect the likelihood of applying peer-editing in their future classrooms. This paper will also explore the conditions that are necessary for teachers to start using peer-editing, and make some general suggestions for teaching practitioners.

It must be pointed out that no generalization about the perception towards peer-editing approach at all levels (primary, secondary, tertiary) can be made until more thorough research is done on each level. This paper hopes to contribute to the existing knowledge on the perception of student-teachers from secondary schools towards the approach after they practiced peer-editing among themselves.

\section{Findings}

Eight out of fifteen questionnaires were finally received (See Appendix 1). Among the received questionnaire, it showed that only one out of eight student-teachers had tried to use peer-editing in her writing class before the course. After the course, three of them said they would try to use peer-editing, another three said they might use some form of peer editing in their classes, while two of them said they would not use peer-editing unless the external constraints are solved. This indicates two things.

First, after practicing peer-editing among themselves no participants showed resistance to using peer-editing by making negative remarks. This to a large extent is thanks to the successful implementation of peer-evaluation and fostering of an atmosphere of mutual-learning by the instructor, Ms Liu Ngar Fun. Those who said "yes" in Question 4 of the questionnaire: After taking this course, would you use peer-editing in your classroom? went on to explain by giving their reasons in Question 5: Referring to Question 4, why/ why not? Appreciation of the benefits of peer-editing was noticed. The following are some of the positive remarks:

\section{"Peer-editing can let students identify problems themselves." \\ "It [peer-editing] seems beneficial. During the process, students can learn something concrete."}

Second, positive experience alone, nevertheless, is not sufficient for teachers to adopt peer-editing. In other words, it is only one of the necessary conditions. There are other factors which may be equally important in order for peer-editing to be used in Hong Kong classrooms. Again, Question 5 sheds light on these factors. Those who answered "no" or "maybe" to Question 4, explained their reservations and resistance in the next question. Since one of the factors that affect student teachers' choices of either using peer-editing or not lies in how they view it socially and theoretically. Therefore, it is worthwhile to see the reasons why they chose against it. Their remarks are listed as follows.

"It [peer-editing] is too time-consuming and most students believe in teachers, not classmates."

"The class size is too large. It is too time-consuming."

"Most students do not trust their peers' comments."

"The students are lacking in enough linguistic knowledge."

"The Education authority, the school and the English panel do not advocate this practice."

"Changes are likely to occur only when the Education authority, the school as well as the English panel start advocating peer review in HK English classrooms. "

\subsection{The Locus of Control}

Rotter's (1954) social learning theory of personality triggered the investigation of people's beliefs in where control over their actions lie. The concept of locus of control can be understood with two sets of extremes. They can be either 'internal', which means a person believes that he/she has direct influence on events happening, or 'external', that is, a person believes that factors out of his/her control contributes to events. In reality, people's locus of control often lies in somewhere between the two extremes; however the differentiation between the two extremes helps shed some light into the following investigation of teachers' responses.

The reasons that peer-editing is not likely to be used can be summarized in a table (See Table 1). They fall into two categories: the external factors and the internal factors. The former has to do with the environment (i.e. time constraints, class size, training and etc.) while the latter has to do with attitudes and perceptions, that is, how teachers view 
peer-editing. Furthermore, the former is related to the recognition of the feasibility of peer editing (questions of how) while the latter is the confirmation of the necessity and benefits of peer-editing (questions of why).

It is necessary that both the favorable external and internal conditions have to be achieved for teachers to begin using peer-editing. If teachers do not foresee any benefits of using peer-editing, it will be unlikely that they apply it in their classes. If a teacher sees the necessity and benefit of it but with many unfavorable external conditions, it can be very difficult for him to apply peer-editing in his classroom.

Ostensibly, the data coming from Questions 4 and 5 "After taking this course, would you use peer-editing in your classroom, why/ why not?" suggest that all of the reasons they provided seemed to be external, and none was concerned with negative attitudes towards peer-editing. However, a closer look reveals that part of the reasons they gave might not be purely external but rather a mixture of both external and internal factors if not entirely internal.

\section{Discussion}

In the following section, I am going to go into details of the responses gathered from the questionnaire and the interview. Suggestions to solve any difficulties will also be made.

\subsection{External constraints}

\subsubsection{Perceived time constraint:}

Peer editing is more complex than traditional teachers' markings. Drafting and revising also take up more time than ordinary product-oriented approaches. A feeling of insufficient time for practicing peer-editing was generally observed from the data collected.

In the communication, a teacher said it is impossible for her to use peer-editing because of the limited class time (A. Hui, personal communication, April 17, 2007). When asked about how much time was needed in a follow-up interview, she said she had no idea as she was inexperienced. It seemed that the perceived difficulties and barriers originated from a lack of experience and training.

It should be noted that some successful cases of exercising peer-editing in tight schedules can be made known to the student teachers, so they can be convinced of the possibility of peer-editing by seeing some successful models. Pennington, Brock \& Yue (1996) managed to implement process writing project in eight Hong Kong secondary classes in three phases of process writing with each phase being four or more lessons. Heron \& Curtis (1999) succeeded in incorporating a six-hour unit on process writing in three weeks. Ho (2006) wrote the following remarks:

"It seems that this program [employing the process approach to teach writing in six Hong Kong primary classrooms] was workable from the Primary 3 to Primary 5 level. From this study, it can be seen that the program could be successfully implemented within a tight schedule (a double lesson each week for seven weeks) and a tight syllabus in all the schools, though it would be more desirable if the duration of the program could be longer"(p. 18).

Ho's study was to mainly investigate the effects and perception of the process approach rather than peer-editing, which is just a small portion of the overall approach and serves as a means to achieve independent writing. Nevertheless, its success is a manifestation of the feasibility of the process-approach, although one can argue that the approach may not work in a specific teaching context, like Hong Kong's secondary education; however, with proper training and successful paradigms to model after, teachers should have a way to implement peer-editing in their classrooms without having to worry about the process being too "time-consuming". University and education institutes also share the responsibility of letting their students know the successful cases of implementing peer-editing so that they would not be intimidated and feel they are the only ones who are carrying out the 'innovative' tasks.

\subsubsection{Large class size:}

Two respondents wrote that they felt the big class-size was a problem for peer-editing. A respondent said in the follow-up interview that she not only had to help students on their individual papers, but also had to monitor all the students and control the class discipline during the peer-editing process.

“We have to monitor the students' discipline. Be practical. We have to mark their essays anyway. It would not make our work any easier. On the contrary, monitoring students' work [work during peer-editing] increases our workload" (A. Hui, personal communication, April 17, 2007).

In other words, the effort made in monitoring the students while they peer-edit other students' papers combined with the effort it takes for teachers to help students on their individual papers adds up to more effort than the teachers are willing to make. It is true that if the students are too recalcitrant and keep disturbing the class, they will do that anyway, not only limited to a peer-editing class. So, discipline issues are not necessarily limited to a class on peer-editing. Interestingly, the same respondent also admitted that this monitoring pressure, being a technical problem and not a problem of peer editing per se, could be solved by providing training for students at an early stage of their education, so that students would know what to do and what not to do. This can help avoid students' idling away precious time during 
in-class peer-editing because they are not 'occupied'. But how much time is needed to train students?

There are different suggestions on the time needed for a peer-training period, during which time students are taught how to give and receive peer-feedback. A few writers have recommended complete peer-feedback training (Manglesdorf, 1992; Brock, 1994; Garratt, 1995; Cheng \& Warren 1996, cited in Heron \& Curtis, 1999). Others found that a shorter period of peer-training (see Miller \& Ng, 1994, cited in Heron \& Curtis, 1999) is desirable. A plausible conclusion to draw is that it is up to the discretion of teachers to apply a suitable amount of time on training their students for peer-editing based on the objective of the peer-editing tasks and the language standards of the students.

I contend that the goal of peer-editing should be made very clear in order to facilitate the process. The more specific a task is, the easier and better the task is managed. For example, for primary students, peer-editing on punctuation is a reasonable and manageable task according to their level.

In addition, there are some useful and easy materials available for teachers to facilitate more effective peer-editing. A simple example of an introduction sheet explaining its purposes and the correct attitude and behavior is given by Hyland (2003, p202). A peer response sheet is also provided by Hyland (2003, p211). These are easy to complete and manageable for teachers and learners. Through these aids, learners know the focus of what they are looking for and time and effort can be saved from monitoring students in a big class.

It should be noted that the success of peer editing in one set of circumstances may not be transferable to another set of circumstances. The local teaching context and culture that the student teachers are in can be greatly different from one another in terms of class size, students' standards of English, etc. Nevertheless, it is the teachers who should bear the responsibility of putting forth the time and effort in developing the concrete ideas for exercising peer-editing in their classes. It will be better for teachers to 'tailor-make' peer-editing in their own class settings based on different factors such as given time constraints, their students' standards of English and the goal of peer-editing.

\subsubsection{Unequal power relation:}

The final external constraint claimed by the student-teachers is the unequal power relation between teachers and the Authority. A number of teachers expressed concern that peer-editing had long been disregarded by the school and the authority.

"The Education authority, the school and the English panel do not advocate this practice."

"Changes are likely to occur when the Education authority, the school and the English panel start advocating peer review in HK English classrooms."

It is conceivable that some schools may not be very supportive in teachers' exercising peer-editing; however, this fact alone is not a convincing argument that the practice should be forsaken without an attempt to experiment it. By saying the problem is "not on my side" or something is "out of my control", some teachers in Hong Kong could be seen as uninvolved and without a crucial role to play. Most teacher I believe would concede there are degrees of flexibility in teaching. When it comes to freedom in the classroom, Hong Kong is not necessarily more confining than other countries. Anecdotal evidence from an interview with two overseas students indicates that schools in the United States do not have clear stipulated guidance for teachers either. In other words, it is to a large extent up to the individual teachers' preference to apply peer-editing or not. Their words may perhaps shed some light to the situation in Hong Kong.

"It is individual teachers' decision to try [peer-editing] or not to try. Usually, teachers who use peer-editing are regarded as better teachers. Those who don't are seen as lazy and not up to his job" (T. Foley, personal communication, March, 28, 2007).

"Peer-editing was used in my middle school a lot. But there were some teachers who did not use it though. The school did not tell the teachers what to do or what not to do. It is a teacher, who teaches, not the school" (J. Chan, personal communication, April, 22, 2007).

On the school administrative side, although there is little data or evidence to show how much pressure exerted from a higher power entity (the Authority) on a lower entity (teachers) may lead to a depletion of freedom thus leading to the abandonment of one's teaching philosophy, it is nevertheless a good idea for the school to provide more freedom, flexibility and support to teachers in exercising their individual teaching philosophies.

On the teachers' side, it may be true that the external constraints may contribute to a certain degree of reluctance in applying peer-editing in classrooms; however, teachers should at the very least consider whether these constraints are really exerted by an external body or just their own idiosyncratic predispositions or unjustified and convenient excuses, rooted in their individual teaching preferences due to a dearth of practical experience in peer-editing. Above all, are the so-called external factors merely external or are they bound to be affected by the internal side of teaching practitioners? 
This paradox of 'dichotomy' will be discussed in the rest of the essay.

\subsection{Internal factors}

4.2.1 Attitude and perception-Failing to see the benefits:

Perception is how people conceptualize their surroundings and environment. Positive attitudes towards peer-editing are one of the factors that will lead to the decision of applying it in class. Doubts of the feasibility of peer-editing, for example, the wild conjecture that pupils may lack the knowledge and competence, were observed among the respondents and should be addressed before any assertions against the external constraints made, as the perceptions determine whether or not a teacher is willing to tackle the objective constraints. In other words, before teachers use peer-editing in class, they have to see its benefits first so that they are willing to keep adjusting the process of peer-editing and try their best to overcome any practical difficulties ahead.

\subsubsection{Lack of knowledge:}

The concern of a lack of knowledge of language skills was noticed among student teachers. Let us go back to the following comments from the student teachers.

"The students are lacking in enough linguistic knowledge."

"Most students do not trust their peers' comments."

In addition to this, the perceived expertise is also a problem. The wish that students preferred teachers' corrections to peer-comments was expressed in several questionnaires collected. Interestingly enough, these comments were from those teachers who had not used peer-editing before. The thought of the plausible lack of knowledge or competence in the students is at best some mere conjecture or at worst some perverse perceptions of difficulties in peer-editing, which are not buttressed up with empirical evidence or practical experience of teachers' using peer-editing. It may be true that if they had tried peer-editing in class, they might not have doubted the students' ability and preference as much as they do now.

As for the students' abilities and competence in using peer-editing, it should be noted that the purpose of which, other than the ultimate aim of developing their language competence, is to develop the ability to reflect on their own work, to critically view their peers' work and eventually to make peer-editing as a habitual and routine activity so that they can further improve the target language by themselves later. Another point that should not be overlooked is that the ability of peer-editing develops over a period of time. It does not do justice for novice-writers to bear all the responsibility for the results of peer editing in a relatively short period of time. Although it may be true that some students do not fully acquire all the necessary language skills for peer-editing's purpose, it does not necessarily follow that peer-editing per se is infeasible as the success of which mainly rely on the level of targets teachers and students set.

Falchikov \& Goldfinch (2000) carried out a meta-analysis of 48 quantitative peer assessment studies by comparing peer and teacher marks and demonstrating that students are generally able to make reasonably reliable judgments. It may help the teacher to ease their worries if they are made aware of this information. Furthermore, teachers should give sufficient introduction to students explaining the purpose and goal in peer-editing and exhibiting the vicarious confidence in them even before peer-editing starts. I contend that peer-editing can be implemented with ease as long as the objectives of the peer-editing are thoroughly negotiated, clearly stated and firmly based on the students' standards of English prior to its commencement.

Research has already found out the relationship between students' attitudes and teachers' attitudes towards a teaching practice. Pennington (1996) found that the students' feelings towards process-writing are influenced by the teacher's attitudes in the onset of the project. In other words, if a teacher holds positive opinions and show more enthusiasm about peer-editing, their students are likely to be affected and feel the same way as the teacher does. If the teacher truly believes peer-editing is beneficial to the students, then students will also find the process worth their time and effort. To a large extent, it is true that teachers bear most of the responsibility in fostering a conducive atmosphere and helping students to form a correct perception of the required expertise.

\section{Conclusion}

In short, resistance and reservations towards adopting peer-editing in classes were observed among the student-teachers upon completion of a second language writing course, which had peer-editing one of its teaching approaches. Both the objective constraints from the teaching context and the subjective teachers' skeptical opinions about peer-editing are believed to lead to the reluctance of teachers implementing peer editing. It seems that when it comes to peer-editing, there are many concerns about the problems of external constraints. At first glance, from the results of the questionnaire, a perceived constraint of time, large class-size, and unsupportive superiors were ostensibly the factors provided by the teachers in explaining why they felt so reluctant in using peer-editing.

A close scrutiny, however, reveals that the teachers were hesitant in implementing such a process-oriented approach in 
writing not because of the mere external factors, but in fact, of a combination or a continuum of both the external and internal factors. The internal factors include the opinions of peer-editing held by both the teachers and students. The teachers' concern about the external factors, e.g. time or class-size, was coupled by their perception of how beneficial and feasible they viewed the approach to be. I contend that however teachers feel about the process, they should consider which of the external constraints (if any) or internal resistance, are preponderant factors in not using peer-editing. This may help to purge themselves of any prejudices arising from their individual preferences.

If these perceived internal and external factors are left unattended, the chances of teachers implementing peer-editing in their classrooms are slim. To overcome these barriers, there are several steps the teachers could take.

\subsection{Tips to implement peer-editing successfully}

The local teaching context that the student teachers are in can be very different from one another in terms of the class size, students' standards of English and etc. Therefore, it is a better idea for teachers to 'tailor-make' peer-editing to suit their own classes based on the level of time constraints, students' standards of English and, most importantly, the goal of peer-editing.

It will be a good idea for the school to give more room and freedom for teachers to apply their own teaching philosophy. The more passionate the teacher is concerning his/her subject, the more impassioned the students will likely be. The difference between a product-oriented approach and a process-oriented approach is that in the product-oriented class, teachers are required to teach towards a specific test or paper, the eventual product, short-term and easily forgotten; but, a process-oriented class is one that focuses on growth, not only of the product itself, but also the creator. Teachers who are free to apply their own teaching methods are able to teach students using methods they will remember for the rest of their lives.

\section{References}

Boud, D. (1995). Enhancing Learning through Self Assessment London, Kogan Page.

Curtis, A., \& Heron, A. (1999). On being less innovative: Peer groups and process writing in Hong Kong. Asia Pacific Journal of Language in Education, 1(1), 99-118

Falchikov, N. (2001). Learning together: peer tutoring in higher education London, Routledge Falmer.

Falchikov, N \& Goldfinch, J. (2000). Student peer assessment in higher education: a meta-analysis comparing peer and teacher marks. Review of Educational Research, 70 (3), 287-322.

Gibbs, G. (1999). Using assessment strategically to change the way students learn. In S. Brown \& A. Glasner, (Eds), Assessment Matters in Higher Education Maidenhead, SRHE and Open University Press.

Hyland, K. (2003). Second language writing. Cambridge: Cambridge University Press.

Ho, B. (2006). Effectiveness of using the process approach to teach writing in six Hong Kong primary classrooms. Perspectives: Working Papers in English and Communication, 17(1)

Liu, N. F. \& Carless, D. (2006). Peer feedback: the learning element of peer assessment. Teaching in Higher Education, 11(3), 279-290.

Pennington, M.C., Brock, M. N., \& Yue, F. (1996). Implementing the writing process in Hong Kong Secondary schools: What the students' response tells us. Perspectives Working Papers of the Department of English, City University, 8(1), 150-217.

\section{Appendix 1}

A study on student teachers 'perception of peer editing in a university course of SLW

1. Did you participate in the peer-editing for at least two out of the three 30-minute papers?

2. Before taking this course, did you use peer-editing in your classroom?

3. Referring to the question 2 , why/ why not?

4. After taking this course, would you use peer-editing in your classroom?

5. Referring to the question 4 , why/ why not?

6. If there is any change in your view, what would you think is the most probable reasons for the change? 


\section{Appendix 2}

Table 1. A comparison of External factors and Internal factors

\begin{tabular}{|l|l|l|}
\hline & External factors & Internal factors \\
\hline Examples & $\begin{array}{l}\text { e.g. Time, class size, local } \\
\text { culture, tradition and practice of } \\
\text { individual schools and settings }\end{array}$ & $\begin{array}{l}\text { e.g. Attitudes and perception of } \\
\text { peer-editing held by individual } \\
\text { teachers }\end{array}$ \\
\hline $\begin{array}{l}\text { Skeptical beliefs about peer } \\
\text { editing held by teachers }\end{array}$ & Feasibility of peer-editing -How & Benefits of peer-editing -Why \\
\hline
\end{tabular}

From the table, we can see the external side concerned with feasibility, and the internal side concerned with benefits. If the adverse external factors can be nicely avoided, e.g. the problems with class size and time constraints, then it would mean the feasibility issue is also addressed. That is, the question "How can we implement peer-editing?" is answered. If the favorable internal factors are satisfied, that is, for teachers to hold positive opinions about peer-editing, then the question of "Why should we implement peer-editing?" must be answered first. 